\title{
Contribuições de Hall para uma analítica de raça e etnicidade no Brasil
}

\author{
Erik W. B. Borda ${ }^{1}$
}

\section{Resumo}

O objetivo deste trabalho é, em um sentido mais amplo, apresentar as contribuições que os Estudos Culturais, ou mais especificamente um de seus autores, Stuart Hall, pode trazer às Ciências Sociais. Produções recentes já trataram de realizar um esforço similar, como Andreas Hofbauer (2009) acerca das possibilidades de intercâmbio entre a Antropologia e a teoria póscolonial e Sérgio Costa (2006), este por sua vez voltando-se à Sociologia. Desse modo, tendo em vista o esforço já previamente realizado por esses autores e os limites deste texto, atentar-me-ei à forma distinta com a qual a perspectiva pós-colonial e os Estudos Culturais, tal como aparecem em Hall, têm lidado com questões de raça e etnicidade. Esse esforço requer, em primeiro lugar, uma crua caracterização do que vejo como dois paradigmas mais comuns no trato dessas questões no cenário brasileiro. Apenas em seguida posso indicar as distâncias que a abordagem de Stuart Hall toma e suas diferenças e contribuição para o debate brasileiro. Por fim, devo acrescentar que o exercício aqui empreendido se vincula intimamente a minha pesquisa de iniciação científica, a qual visa a identificar os eventuais impactos da obra de Hall no Brasil.

É importante dizer que o campo de estudos sobre raça e etnia no Brasil é muito amplo, sendo assim difícil definir com clareza onde começa e onde

\footnotetext{
1 Iniciação Científica - Universidade Federal de São Carlos - Departamento de Sociologia. Orientador: Valter Roberto Silvério.

E-mail: ewbborda@gmail.com
} 
termina cada abordagem. A divisão que se segue deve ser entendida, pois, como típica-ideal. É também imprescindível apontar o fato de que seguimos uma pista deixada por Hall no texto Race, articulation and societies structured in dominance (1980), que através do mesmo processo - a identificação de tendências dominantes na Teoria Social para, por fim, apresentar sua própria - demonstra as insuficiências de análises acerca de formações sociais racialmente estruturadas. Segundo Hall (idem), as duas tendências dominantes por ele identificadas podem ser chamadas de a "econômica" e a "sociológica", as quais como muitas vezes ocorre a paradigmas rivais, terminam por parecer reflexos invertidos uma da outra. A primeira "toma as estruturas e relações econômicas como dotadas de um efeito completamente determinante sobre as estruturas sociais de tais formações [racialmente estruturadas]." ${ }^{\prime 2}$ (idem. p. 306) Os autores da segunda, a sociológica, "embora difiram internamente [...] concordam com a autonomia e o não-reducionismo de raça e etnicidade como aspectos sociais." ${ }^{3}$ (idem) Neste texto tratarei as tendências brasileiras de maneira análoga, são o que chamarei respectivamente de Sociologia das relações raciais e Antropologia das populações afro-brasileiras.

A Sociologia das relações raciais pode ser apreendida de maneira exemplar em Florestan Fernandes, ou de modo mais geral, nos autores oriundos daquilo que se convencionou chamar, um tanto controversamente, de Escola Paulista de Sociologia. O que marca os membros dessa tendência como pertencentes a um corpo analítico comum - e volto insistir no quão são internamente variáveis os autores e as análises que se enquadram dentro das duas tendências - é, antes de tudo, a tentativa de pensar os problemas

\footnotetext{
22 Tradução livre.
}

3 Tradução livre. 
advindos da questão racial mais como uma questão de desigualdade, a qual é vista em direta conexão com as relações materiais de produção. Isso não significa dizer que os estudos dessa vertente não pensaram questões como o "preconceito racial"4 - por excelência no universo dos valores -, por exemplo, muito pelo contrário. O ponto, na verdade, é que reflexões desse tipo voltaram-se mais ao que sofre o "povo negro", sem se questionar o que faz um povo ser negro ou mesmo o que seja "ser negro" - quase sempre visto de maneira não problemática, como aquele que é ex-escravo, um estrato social, em meio a uma sociedade de classes precária. Reflexões como essa foram importantíssimas, em especial porque a preocupação em solidificar as análises com abordagens quantitativas fortaleceu a empreitada de levar a questão do racismo à esfera de consciência nacional, assim como a centralidade da desigualdade como pauta teórica orientou parte significativa da agenda política do movimento negro. Havia, assim, uma ênfase sobre a questão das oportunidades usufruídas (ou não) pelos negros, e as interpretações sobre a questão se voltavam menos às dimensões dos valores e da cultura do que às dinâmicas socioeconômicas, em grande parte desagregadoras, da sociedade brasileira em transformação.

A segunda abordagem, antropológica, voltou-se estritamente ao mundo da cultura, e por sua vez enfatizando o não-reducionismo de raça e etnicidade às estruturas sociais, sejam estritamente econômicas ou não. Em contraste com a anterior, ao invés de pensar o preconceito racial como um "arcaísmo do passado", forma característica de Florestan, a abordagem antropológica destaca a especificidade de raça enquanto um fator culturalmente constitutivo da sociedade brasileira - mas não só. Grosso modo, os estudos voltaram às construções, reconstruções, heranças e etc. de

\footnotetext{
${ }^{4} \mathrm{O}$ termo racismo aparece nessas vertentes apenas posteriormente.
} 
África entre as populações negras brasileiras, muitas vezes indicando suas contribuições para a "cultura" ou "identidade" nacional, e tendem a pensar de maneira autônoma cada um dos discursos que constroem diferenças. As duas abordagens, assim, distinguem-se mutuamente na medida em que, como diz Hall, a primeira "tende a ser monocausal em forma, [e] a última tende a ser pluralista em ênfase" . (id. ibid. p.307) Em suma, etnia na tendência aqui esboçada é apenas mais um aspecto de elementos, nos quais raça pode não ocupar o posto central.

Devo enaltecer que esses debates expressados pelas duas tendências não se limitam a questões puramente teóricas, uma vez que as diferenças nas análises têm efeitos reais sobre as estratégias de transformação política no Brasil. Por exemplo, se a ênfase recai sobre a dimensão econômica, a mera transformação desta acarretaria a desaparição de problemas derivados de raça e etnia. Se a segunda tendência for a alternativa, a transformação econômica não será suficiente, fazendo-se necessárias políticas que foquem e respeitem a especificidade de raça e etnia enquanto fatores sociológicos autônomos.

O foco desta apresentação é mostrar que a perspectiva de articulação dos Estudos Culturais, ou mesmo o que pode ser tido como uma de suas expressões mais sofisticadas correntes atualmente, a saber, a ideia de intersecção, dá uma resposta diferente à problemática. Por um lado a primeira tendência está certa em nos chamar a atenção ao fato que as estruturas raciais não podem ser entendidas sem remeter, em algum nível, aos conjuntos de relações econômicas. Por outro lado, a segunda está correta também quando aponta para a especificidade de raça e a importância das "culturas afro-brasileiras" na formação social nacional - incluindo aqui a

\footnotetext{
5 Tradução livre
} 
própria estrutura econômica. O problema principal de ambas as tendências, contudo, é que partem de uma matriz epistemológica racializada. Negro foi uma das categorias 'inventadas' no contexto do colonialismo para apagar a subjetividade dos povos colonizados, quando a diferença intragrupo é jogada fora em pró de algo que os homogeneíze e hierarquize. No caso da primeira tendência isso se torna mais candente. Nela, negro é uma categoria que precede qualquer teorização, trata-se de um grupo dado e imediato da estrutura social sobre o qual certos fenômenos incidem. Há uma uniformização da experiência do que é ser negro que pouco fala acerca das formas complexas através das quais esse grupo é formado, em íntima vinculação com discursos de classe, gênero e sexualidade - para ficar apenas em alguns. Além disso, não raras vezes a primeira abordagem toma o que podemos chamar de uma forma "marxista", ou seja, que tenta derivar de um único aspecto as questões e repostas sobre raça, e a segunda uma forma "weberiana", ou seja, que pensa raça, etnia, gênero, sexualidade, classe e etc. como esferas autônomas, cada uma agindo independentemente uma da outra na produção da alteridade.

A concepção de articulação para Stuart Hall visa a dar conta desse problema teórico, i.e., pensar tanto como o econômico cria um cenário de possibilidades para os vínculos entre os diferentes traços sociais - como gênero, raça e classe - quanto ele é transformado pelos diferentes arranjos por ele próprio possibilitados. Segundo o autor:

Uma articulação é, então, a forma de conexão que pode criar uma unidade de dois elementos diferentes, sob determinadas condições. É uma ligação que não necessariamente é determinada, absoluta e essencial durante todo tempo. [...] A assim chamada "unidade" do discurso é realmente a articulação de elementos 
distintos, diferentes que podem ser rearticulados de diferentes maneiras porque não têm um "pertencimento" necessário ${ }^{6}$ (HALL, 2010a. p. 85).

Com isso Hall tenta chamar nossa atenção para a complexidade necessária de qualquer formação social. Raça, certamente, possui sua especificidade enquanto traço social, mas deve ser tratada com relação às estruturas econômicas de uma dada sociedade. A articulação, assim, visa a vincular diferentes níveis de uma formação social em um todo analítico momentâneo.

Certa feita, W. E. B. Dubois (1999) afirmou que a barreira racial (color line) é o problema do século XX. Deixando de lado a especificidade do que de fato Dubois quis dizer, vou tratar aqui essa afirmativa como uma metáfora de um horizonte norteador de algumas preocupações político-intelectuais do século XX, e que em certo sentido deu molde à Sociologia das relações raciais. Stuart Hall, em outro momento (2010b), diz-nos que a capacidade de viver com a diferença será o grande problema do século XXI, o que, na minha leitura, significa clamar por novos paradigmas interpretativos com o fim de dar conta deste momento. Defendo nesta apresentação, pois, o tipo de teorização comprometido com uma política da diferença, pensada com suas múltiplas intersecções ou articulações com discursos e práticas sociais variadas, que desloque as ênfases das abordagens anteriores, ora sobre a cultura, ora sobre o econômico, ao se trazer à tona os intercâmbios problemáticos desenhados entre eles. Este exercício, em minha visão, pode ser apreciado em Stuart Hall, embora certamente não defenda aqui que este autor tenha sido o primeiro e tampouco o mais importante a trabalhar com a proposta. Quero dizer apenas que certos problemas teóricos podem ser

\footnotetext{
${ }^{6}$ Tradução livre
} 
melhor desenvolvidos tendo-se em vista o tipo de trabalho intelectual levado à cabo por Stuart Hall, uma contribuição sem dúvida inegável às Ciências Sociais no Brasil.

Palavras Chave: articulação, Stuart Hall, raça, pós-colonial, Estudos Culturais

\section{Referências}

COSTA, S. Desprovincializando a Sociologia: A contribuição pós-colonial. In: Revista brasileira de Ciências Sociais. Vol. 21 nº 60 fevereiro/2006.

DUBOIS, W E B. As almas da gente negra. Rio de Janeiro: Lacerda, 1999.

HALL, S. Race, Articulation, and Societies Structured in Dominance. In: Sociological Theories Race and Colonialism. Paris: UNESCO, 1980.

Sobre postmodernismo y articulación. In: Sin garantías: trayectorias y problemáticas en estudios culturales. Popayán: Envión editores, 2010a.

Cultura, comunidad, nación. In: Sin garantías: trayectorias y problemáticas en estudios culturales. Popayán: Envión editores, 2010b

HOFBAUER, A. Entre olhares antropológicos e perspectivas dos estudos culturais e póscoloniais: consensos e dissensos no trato das diferenças. In: Antropolítica (UFF)., v.27, p.99-130, 2009. 